\title{
Morfoanatomia dos órgãos vegetativos de Piper hispidum Sw. (Piperaceae)
}

\author{
Adriana L.M. Albiero ${ }^{1 *}$, Adelita A.S. Paoli, Luis A. Souza ${ }^{3}$, Káthia S.M. Mourão ${ }^{3}$ \\ 'Departamento de Farmácia e Farmacologia, Universidade Estadual de Maringá, Av. Colombo 5790, Campus \\ Universitário, 87020-900, Maringá, PR, Brasil, \\ ${ }^{2}$ Departamento de Botânica, Universidade Estadual Paulista, Av. 24A, 1515, Bela Vista, \\ 13506-900, Rio Claro, SP, Brasil, \\ ${ }^{3}$ Departamento de Biologia, Universidade Estadual de Maringá, Av. Colombo 5790, Campus Universitário, \\ 87020-900, Maringá, PR, Brasil
}

\begin{abstract}
RESUMO: O presente trabalho teve por objetivo o estudo morfoanatômico dos órgãos vegetativos de Piper hispidum, visando a estabelecer características marcantes para a sua identificação e auxiliar estudos taxonômicos e farmacobotânicos. O material vegetal fresco e fixado foi estudado segundo as técnicas usuais de corte e coloração, incluindo análise em MEV. Piper hispidum é um arbusto com caule cilíndrico, nodoso, verde claro, com folhas alternas, ovadas, de cor verde-escura na face adaxial e verde claro na abaxial. Dentre as características anatômicas importantes para sua identificação destacam-se: parênquima cortical da raiz apresentando grupos de esclereídes. Córtex caulinar com faixas descontínuas de colênquima do tipo angular e tecido vascular organizado em dois círculos descontínuos de feixes colaterais. A folha é dorsiventral, hipoestomática, com estômatos tetracíticos. Hipoderme adaxial descontínua e abaxial frouxa com número variável de camadas; tricomas tectores e glandulares ocorrem nas duas faces. Epiderme uniestratificada e idioblastos oleíferos ocorrem em todos os órgãos.
\end{abstract}

Unitermos: Piper hispidum, Piperaceae, morfo-anatomia, farmacobotânica.

\begin{abstract}
Morphology and anatomy of the vegetative organs of Piper hispidum Sw. (Piperaceae)". The morphology and anatomy of the vegetative organs of Piper hispidum are described, detaching remarkable strutural aspects and contributing to taxonomical and pharmacobotanical studies. The material was studied according to the usual techniques, including SEM (Scaning Eletron Microscopy). Piper hispidum is a shrub with cylindrical and green stem, which has alternate leaves. The main anatomical characteristics that can be used in its identification are: root with sclereids on cortical parenchyma, stem cortex with discontinuous strands of angular collenchyma, and vascular tissue constituted by two discontinous circles of collateral vascular bundles. The leaf is dorsiventral and hypostomatic with tetracytic stomata. The hypodermis is discontinuous in adaxial face, loose in abaxial one and presents a variable number of layers. Uniseriate epidermis and oil idioblasts occur in all organs.
\end{abstract}

Keywords: Piper hispidum, Piperaceae, morpho-anatomy, pharmacobotany.

\section{INTRODUÇÃO}

A família Piperaceae distribui-se pelas Américas, do México à Argentina (Yuncker, 1972, 1973; Figueiredo; Sazima, 2000) e no Brasil está representada por cinco gêneros e aproximadamente 460 espécies (Barroso, 1978). Piper L. inclui grande número de espécies de valor econômico indiscutível como condimentos, inseticidas, cosmético e medicinal, devido à produção de óleos essenciais (Silva; Machado, 1999).

Piper hispidum Sw., conhecida como jaborandi ou falso-jaborandi, possui amidas de ação anti-fúngica e é utilizada popularmente no combate a afeccções da pele e cabelos (Navickiene et al. 2000). Recentemente foi realizado uma análise comparativo dos óleos voláteis de algumas espécies de Piperaceae, entre elas, se encontra Piper hispidum (Mesquita et al., 2005; Potzernheim et al
2006).

$\mathrm{Na}$ literatura, dentre os trabalhos sobre morfoanatomia de órgãos vegetativos em Piperaceae, destacam-se os de: Murty (1960), com algumas espécies de Peperomia; Langhammer (1970), com P. auritum H.B.K.; Salatino; Silva (1975), com P. regnellii (Miq.) C. DC. var. regnellii; Datta; Dasgupta (1979), com Piperales; Dasgupta; Datta (1980), com espécies medicinais de Piper; Mohandas; Shah (1982), com tricomas em Piperaceae; Vianna; Akisue (1997), com $P$. aduncum L.; Nascimento; Vilhena-Potiguara (1999) com P. hispidinervium C.DC.; Pessini et al. (2003), com $P$. regnellii (Miq.) C. DC. var. pallescens; Takemori (2002), com espécies de Peperomia e mais recentemente, Souza et al. (2004), com Peperomia dahstedtii C. DC., Ottonia martiana Miq. e $P$. diospyrifolium Kunth. e Albiero et al.(2005), com Piper crassinervium H. B. \& K. 
A grande semelhança morfológica entre as espécies de Piper, como destacado por Pessini et al. (2003) e por Albiero et al. (2005), contribui para problemas de identificação, troca e até mesmo falsificação quando as espécies são coletadas e comercializadas como medicinais.

Este trabalho teve por objetivo estudar os órgãos vegetativos de $P$. hispidum, visando a estabelecer características marcantes para sua identificação e colaborar com estudos taxonômicos, ecológicos e de avaliação de qualidade de materiais comercializados como medicinais.

\section{MATERIAL E MÉTODOS}

O material utilizado constou de raiz, caule e folha de Piper hispidum Sw. coletados de quatro espécimes do Horto Florestal "Dr. Luiz Teixeira Mendes", situado no município de Maringá, PR, Brasil. Exsicatas da espécie estudada encontram-se depositadas como documento taxonômico no Herbário da Universidade Estadual de Maringá, sob número de registro HUM 9137.

Os estudos morfológicos e anatômicos foram realizados em material fresco e fixado. Para fixação foi utilizado FAA 50 (Johansen, 1940), e a conservação foi feita em etanol 70\% (Jensen, 1962).

Seções transversais, longitudinais e paradérmicas foram realizadas à mão livre, com auxílio de lâmina de barbear comum, ou utilizando-se micrótomo de rotação. Para confecção de lâminas permanentes, as peças fixadas foram desidratadas em série etílica, passando em seguida por série xilólica, incluídas em parafina (Sass, 1951), seccionadas, coradas e montadas em Permount. Lâminas permanentes foram também confeccionadas utilizando-se historresina, segundo a técnica descrita por Gerrits (1991). As lâminas semi-permanentes foram coradas com safranina e azul de astra (Gerlach, 1969) e as permanentes com hematoxilina de Erlich (Johansen, 1940) ou com Azul de Toluidina conforme O’Brien et al. (1965).

As seções do material fresco foram submetidas a testes histoquímicos: solução de Sudan IV para localizar paredes suberificadas, cutinizadas e outros materiais lipídicos (Johansen, 1940); solução de cloreto férrico 10\% (Johansen, 1940) dicromato de potássio a 10\% (Gabe, 1968) e vanilina clorídrica (Mace; Howell, 1974) para evidenciar compostos fenólicos; floroglucinol acidificado (Johansen, 1940) para identificação de lignina; reagente de Dragendorff (Svendsen; Verpoorte 1983) e reagente de Wagner (Furr; Mahlberg 1981) para a detecção de alcalóides; reagente de Lugol para localização de amido (Johansen, 1940); solução de vermelho de rutênio (Jensen, 1962) para evidenciar pectinas ou polissacarídios e ácido sulfúrico diluído (5-10\%), para localizar cristais de oxalato de cálcio (Johansen, 1940).

A nomenclatura para descrever os caracteres morfológicos foi baseada em Radford (1974). A diafanização das folhas seguiu a técnica de Fuchs (1963) e a descrição do padrão geral de venação utilizou os critérios propostos por Hickey (1973).

A caracterização morfológica da superfície foliar foi complementada com análise em microscópio eletrônico de varredura (MEV) modelo JEOL JSM - 5410 Scanning Microscope, segundo técnica de Robards (1978) e a descrição foi realizada de acordo com a padronização proposta por Barthlott et al. (1998).

As fotografias foram obtidas com câmera digital Sony modelo DSC-P51 e as fotomicrografias por captura de imagem pelo programa Image Pro-Plus, versão 4.0 (Media Cybertecnics) adaptado a microscópio óptico Olympus BX50. Os desenhos e diagramas foram obtidos com auxílio de câmara clara, adaptada a estereomicroscópio Leica M $3 \mathrm{Z}$ e a microscópio óptico Wild M 20. As escalas referentes às ilustrações foram obtidas utilizando-se lâmina micrométrica nas mesmas condições ópticas utilizadas para cada caso.

\section{RESULTADOS E DISCUSSÃO}

Piper hispidum possui porte arbustivo, medindo cerca de 1,8 a 2,0 m de altura (Fig. 1), caule cilíndrico, de coloração verde-clara, nodoso, áspero, com lenticelas e ramos mais jovens pubescentes (Fig. 4-seta).

As folhas são alternas, simples, curtamente pecioladas, inteiras, de formato ovado, apresentando limbo assimétrico com 15,0-17,0 cm de comprimento e $10,0-12,0 \mathrm{~cm}$ de largura, coloração verde-escura na face adaxial e verde-clara abaxialmente, ápice acuminado e base obtusa (Figs. 3, 15).

Albiero et al. (2005) descrevem características vegetativas semelhantes para $P$. crassinervium, e destacam entre as reprodutivas, como diferença marcante, o odor pungente e característico das espigas desta espécie, que quando maduras são amarelas.

O sistema radicular adventício é extenso, ramificado, constituído por raízes finas que partem da base subterrânea e alargada do caule e assumem posição paralela à superfície do solo (Fig. 4). Sistema radicular semelhante é descrito por Moraes (1986) para Pothomorphe umbellata e por Nascimento e VilhenaPotiguara (1999) para P. hispidinervium. Nesta última espécie, os autores descrevem o sistema radicular como fasciculado, constituído pelas raízes primária, adventícia subterrânea e adventícia aérea.

Souza et al. (2004) destacam para Ottonia martiana e $P$. diospyrifolium um órgão subterrâneo semelhante a um estolão, que se desenvolve paralelamente a superfície do solo e ocasionalmente dá origem a novos indivíduos. Em P. hispidum, assim como em P. crassinervium (Albiero et al. 2005), verifica-se que da base subterrânea e alargada da raiz, partem vários caules aéreos e eretos, não havendo semelhança com estolão. Diante de toda esta variedade de interpretações, tornamse necessários estudos ontogênicos detalhados, para se 
descrever com certeza os tipos de órgãos subterrâneos que ocorrem em Piper.

As raízes adventícias em estrutura primária apresentam epiderme uniestratificada e córtex parenquimático, no qual se observam, mais externamente, grupos de duas a cinco esclereídes posicionadas em círculo. Mais internamente, ocorrem idioblastos contendo material lipofílico e outros esparsos contendo grãos de amido (Figs. 5-6).

Estrutura semelhante é descrita para $P$. crassinervium (Albiero et al. 2005). Entretanto, as esclereídes ocorrem em grupos de uma a três e os idioblastos oleíferos não se diferenciam em tamanho das células do parênquima cortical. Além disso, idioblastos cristalíferos contendo pequenos cristais aciculares, descritos pelos autores para $P$. crassinervium, não foram observados em $P$. hispidum. As raízes da espécie em estudo também assemelham-se às de $P$. aduncum (Vianna; Akisue 1997), P. hispidinervium (Nascimento; VilhenaPotiguara, 1999) e P. regnelli var. pallescens (Pessini et al. 2003), exceto pela ausência das esclereídes nas duas últimas espécies.

Metcalfe e Chalk (1950) descrevem em $P$. betle um estelo limitado externamente por anel de esclerênquima unisseriado e a presença de células secretoras com paredes lignificadas ou suberificadas, além de pêlos nas raízes jovens que gradualmente, nas raízes mais velhas, são substituídos por várias camadas de células corticais. Este anel não foi observado em $P$. hispidum.

As raízes poliarcas apresentam crescimento secundário típico de Dicotiledôneas e se caracterizam pelo xilema bem desenvolvido, pelos raios parenquimáticos largos e pela periderme desenvolvida a partir de felogênio irregular subepidérmico, o qual diferencia pouco súber e feloderme (Figs.7-8). Desenvolvimento semelhante é descrito para P. aduncum (Vianna; Akisue, 1997), $P$. hispidinervium (Nascimento; Vilhena-Potiguara, 1999) e P. regnelli var. pallescens (Pessini et al. 2003).

O caule é cilíndrico e, em estrutura primária, está constituído por epiderme uniestratificada, clorofilada e recoberta por cutícula fina. Nela ocorrem tricomas tectores pluricelulares, unisseriados e lenticelas, ambos esparsos. Faixas descontínuas de colênquima angular estão imersas no parênquima cortical (Fig. 9). O restante do córtex é constituído por células parenquimáticas, com idioblastos cristalíferos, com cristais aciculares de oxalato de cálcio, e idioblastos oleíferos.

Metcalfe e Chalk (1950) destacam em Piperaceae a presença de cristais em forma de drusas, além dos aciculares, grãos cristalinos e arenosos de várias formas.

Vianna e Akisue (1997) descrevem a ocorrência de células mucilaginosas no parênquima cortical de $P$. aduncum, aspecto não observado em $P$. hispidum.

$\mathrm{O}$ tecido vascular está organizado em dois círculos concêntricos de feixes colaterais. $\mathrm{O}$ círculo externo, é delimitado externamente pelo periciclo e endoderme uniestratificados e internamente por bainha perimedular, que se torna esclerificada. $\mathrm{Na}$ endoderme ocorrem estrias de Caspary.

$\mathrm{O}$ círculo interno encontra-se imerso no parênquima medular e mostra distribuição irregular dos feixes vasculares. Nas células deste parênquima, pode ser observado uma grande quantidade de cristais aciculares de oxalato de cálcio, grãos de amido e idioblastos oleíferos sendo que estes, também foram observados no floema dos feixes vasculares externos e internos (Figs. 11, 12).

$\mathrm{O}$ crescimento em espessura ocorre pela diferenciação de câmbio fascicular e interfascicular no círculo externo de feixes vasculares e segue o padrão de desenvolvimento das Dicotiledôneas (Figs. 10-12).

Em estrutura secundária, observa-se a diferenciação de câmbio vascular nos feixes vasculares internos, o qual produz certa quantidade de tecido vascular secundário, principalmente xilema (Fig. 14). Nesta fase, os feixes medulares, mostram-se em maior número e distribuídos de forma difusa, à semelhança das Monocotiledôneas (Fig. 11).

No caule em estrutura secundária, observase epiderme com raros tricomas e periderme associada somente a lenticelas esparsas. O córtex mantém-se como na estrutura primária, exceto pelas células mais internas do colênquima que sofrem lignificação centrífuga (Fig. 12).

A persistência da epiderme, no caule em estrutura secundária, também ocorre em $P$. hispidinervium (Nascimento; Vilhena-Potiguara, 1999) e P. crassinervium (Albiero et al., 2005). Em P. aduncum, Vianna e Akisue (1997), descrevem uma periderme delgada, cujo felogênio se origina na epiderme. A ocorrência de periderme também é descrita por Pessini et al. (2003) em P. regnellii var. pallescens.

De acordo com Mauseth (1998), o aparecimento de lenticelas pode ou não estar associado com o desenvolvimento de periderme, e em geral, na ausência desta diferenciação, seu aparecimento está relacionado à atividade mitótica do parênquima logo abaixo dos estômatos. Se os estômatos são raros, as lenticelas originam-se pela atividade de trechos de felogênio que surgem dispersos entre as células epidérmicas, como ocorre em P. hispidum.

O colênquima em faixas e sua gradual esclerificação centrífuga são citados também para $P$. aduncum (Vianna; Akisue, 1997), P. hispidinervium (Nascimento; Vilhena-Potiguara, 1999), P. dyospyrifolium e Ottonia martiana (Souza et al. 2004). Entretanto, em $P$. regnellii var. pallescens e $P$. crassinervium, o colênquima torna-se contínuo em regiões mais velhas do caule (Pessini et al. 2003).

A endoderme com estrias de Caspary também é observada no caule em estrutura secundária (Fig. 13), à semelhança de outras espécies de Piper descritas por Bond apud Metcalfe e Chalk (1950) e em P. aduncum por Vianna e Akisue (1997) e por Souza et al. (2004) em P. 
diospyrifolium e Peperomia dahlstedtii.

Melo-de-Pinna e Menezes (2002) mencionam a existência de endoderme em todos os órgãos de Ianthopappus corymbosus (Asteraceae) e que tal fato demonstra o conceito da continuidade dos tecidos nas plantas, enfatizando que a endoderme, a camada mais interna do córtex, origina-se de um meristema fundamental, podendo diferenciar-se em uma bainha amilífera ou uma bainha parenquimática, com ou sem estrias de Caspary.

Em $P$. hispidinervium, a endoderme está presente no caule em estrutura primária e secundária e na nervura principal está diferenciada em uma bainha amilífera (Nascimento; Vilhena-Potiguara, 1999).

Em Peperomia catharinae, Peperomia emarginella, Peperomia quadrifolia e Peperomia rotundifolia, descritas por Takemori (2002), a endoderme também está presente envolvendo os feixes vasculares mergulhados no parênquima medular, constituindo monostelos como em algumas Monocotiledôneas.

Lersten (1997) em seu trabalho de revisão sobre a presença de endoderme em caules e folhas, menciona que esta camada é comumente observada nos caules de espécies de Pteridófitas, incomum ou ausente nas Gimnospermas e de ocorrência pontual nas Angiospermas. Metcalfe e Chalk (1950) descrevem esta camada em 25 famílias de Dicotiledôneas, não mencionando, entretanto, qual seria sua verdadeira função.

Burger (1958) destaca que Piperales apresentam caracteres comuns a várias Monocotiledôneas, que são raros ou incomuns em Dicotiledôneas, mais especificamente quanto à organização do sistema vascular.

Dahlgren e Clifford (1982) destacam a hipótese de que as Piperaceae representam um grupo de transição entre Mono e Dicotiledôneas, visto que ambos os grupos originam-se de um tronco comum.

Vários autores, como Metcalfe e Chalk (1950), Yuncker (1958), Murty (1960), Langhammer (1970), Hutchinson (1973), Cronquist (1981) referem-se aos feixes vasculares distribuídos de modo semelhante aos das Monocotiledôneas em Pipereceae. Trabalhos recentes como os de Vianna e Akisue (1997), Nascimento e Vilhena-Potiguara (1999), Takemori (2002), Pessini et al. (2003), Souza et al. (2004) e Albiero et al. (2005) também discutem este aspecto.

Segundo Judd et al. (1999), análises cladísticas baseadas na morfologia e nas seqüências genéticas de rRNA, rbcL e atpB, não apóiam a divisão tradicional das Angiospermas em Monocotiledôneas e Dicotiledôneas. De acordo com estas análises as Piperaceae, antes incluídas nas Dicotiledôneas, passaram ao grupo das paleoervas, juntamente com Nymphaeaceae, Aristolochiaceae e Ceratophyllaceae.

Takemori (2002) afirma que os trabalhos de anatomia do caule envolvendo ontogênese, anatomia nodal e arquitetura estelar são de grande relevância para um melhor entendimento da evolução dos caracteres de Piperaceae, e poderiam explicar o vínculo entre Pteridospermas, Magnoliopsida e Liliopsida.

A folhas de P. hispidum apresentam base assimétrica e pecíolo curto, reto e aproximadamente circular em seção transversal (Figs. 15, 21-22)

$O$ padrão geral de venação é do tipo camptódromo-broquidódromo. A nervura central é proeminente em toda a extensão da folha, afilando-se em direção ao ápice (Fig.15).

As nervuras secundárias que dela partem são ascendentes, ligeiramente curvas, alternadas, e se posicionam no terço inferior do limbo, em número de dez (Fig. 15). A rede de nervuras terciárias é do tipo perpendicular, subdividida por veias quaternárias e de quinta grandeza, formando aréolas pentagonais com vênulas que se ramificam até três vezes. A venação marginal é do tipo fimbriada (Figs. 16-17).

O pecíolo apresenta epiderme uniestratificada, recoberta por cutícula e apresentando tricomas tectores pluricelulares e unisseriados. Faixas descontínuas de colênquima angular, constituídas por 8 a 11 estratos de células, ocorrem imersas no parênquima cortical, opostas aos onze feixes vasculares colaterais de tamanho uniforme e dispostos de forma circular. Idioblastos oleíferos ocorrem na região subepidérmica e por todo parênquima fundamental (Fig. 22) que também apresenta cristais aciculares. Esta estrutura mantém-se até a região basal do limbo, havendo diminuição no número de idioblastos oleíferos (Figs. 20-21).

$\mathrm{Na}$ nervura central há redução no número de feixes vasculares, ocorrendo dois na região mediana do limbo e apenas um no ápice. O colênquima angular fica restrito a duas faixas subepidérmicas na face abaxial e a uma faixa na face adaxial na região mediana. No ápice, na face adaxial, ocorre uma faixa muito reduzida de colênquima (Figs.18-19).

A epiderme do limbo é uniestratificada, constituída por células cúbicas e recobertas por cutícula espessa. Três tipos tricomas tectores são observados: curto, de extremidade unicelular aguda; curto, pluricelular, de base alargada e de extremidade afilada e ainda um longo, pluricelular, unisseriado, de extremidade também afilada. Apenas um tipo de tricoma glandular ocorre, apresentando pedúnculo unicelular e célula secretora de formato ovóide inclinada sobre a epiderme (Figs. 23-25, 29-34).

Os tricomas tectores curtos de extremidade aguda são observados em maior quantidade na face adaxial (Fig. 29) enquanto que os outros dois tipos ocorrem preferencialmente na face abaxial, principalmente sobre as nervuras (Fig.25). Os glandulares também, são mais evidentes na face abaxial (Figs. 32).

Observações em MEV, mostram que nas células epidérmicas nas faces abaxial (Figs. 29-31) e adaxial (Figs. 32-34) a cutícula espessa forma crostas no limite entre uma célula e outra, sendo estriada sobre os tricomas tectores. Na base dos tricomas tectores a cutícula é lisa e 
encontra-se elevada em relação a superfície epidérmica.

Os tricomas segundo Metcalfe e Chalk (1950), ocorrem nas folhas de todos os gêneros de Piperaceae, e raramente formam uma densa cobertura.

Mohandas e Shah (1982) descrevem a estrutura e a ontogenia dos tricomas de espécies de Piper, Peperomia e Lepianthes diferenciando-os em não glandulares, glandulares, unicelulares, unisseriados bicelulares e unisseriados pluricelulares, denotando ser este um caráter importante para a distinção entre as espécies.

Dos tricomas descritos pelos autores acima, três deles assemelham-se aos de P. hispidum: o tricoma tector curto, de extremidade afilada, o glandular descrito para $P$. betle var. pudukodi, e o tricoma tector longo para $P$. hookeri. Convém destacar que nestas duas espécies além destes, ocorrem outros tipos de tricomas.

Os tricomas tectores unisseriados e o glandular descritos para $P$. aduncum por Vianna e Akisue (1997), assemelham-se aos encontrados em $P$. hispidum. Entretanto, em $P$. aduncum os autores descrevem ainda um outro tipo, o tricoma tector pluricelular capitado.

Tricoma glandular e tector curto, como os de $P$. hispidum, são os dois únicos tipos descritos para $P$. hispidinervium (Nascimento; Vilhena-Potiguara, 1999). Em $P$. crassinervium (Albiero et al., 2005) e $P$. regnellii, var pallecens (Pessini et al., 2003) foram observados somente tricomas glandulares ovóides.

A folha é hipoestomática apresentando estômatos tetracíticos e raros anisocíticos (Fig. 24).

Em $P$. hispidernervium, Nascimento e VilhenaPotiguara (1999) descrevem a folha como anfiestomática e mostraram a predominância dos estômatos tetracíticos, mas descrevem a ocorrência de ciclocíticos e anisocíticos.

Em P. aduncum, Vianna e Akisue (1997) observaram estômatos tetracíticos e em $P$. regnelli var. pallescens, Pessini et al. (2003) observaram somente ciclocíticos.

Metcalfe e Chalk (1950) denominam como ciclocíticos os estômatos característicos em Piperaceae.

Segundo Takemori et al. (2003) em seu estudo sobre a ontogênese dos estômatos em quatro espécies de Peperomia, o aparelho estomático parece ser um caráter pouco útil para taxonomia de Piperaceae, devido a complexidade e variação morfológica dos mesmos, afirmação feita também por Souza et al. (2004)

O mesofilo é dorsiventral com parênquima paliçádico uniestratificado e lacunoso constituído por duas a quatro camadas de células isodiamétricas, onde ocorrem idioblastos oleíferos, que parecem estar em maior número quando comparados aos demais órgãos vegetativos (Fig. 26-28).

Em $P$. hispidum os idioblastos oleíferos são muito semelhantes aos descritos por Fahn (1979), como "oil sacs", por tratarem-se de células usualmente isoladas que diferenciam-se das células vizinhas em tamanho e forma, contendo gotas de óleo (substâncias lipídicas).

383 Rev. Bras. Farmacogn.

Braz J. Pharmacogn.

16(3):jul/set. 2006
Em ambas as faces, abaixo da epiderme, observam-se estratos variáveis de células aclorofiladas, apresentando-se descontínuo na face adaxial com uma a três camadas e contínuo e frouxo na face abaxial, constituído por dois a três estratos (Figs. 26-28).

Takemori et al. (2003) descrevem nas folhas de espécies de Peperomia a presença de tecido aqüífero desenvolvido a partir de divisões periclinais das células protodérmicas da face abaxial da folha, caracterizando, uma epiderme múltipla. Souza et al. (2004) também descrevem a presença de epiderme múltipla em Peperomia dahlstedtii.

Souza et al. (2004) mencionam para Ottonia martiana e $P$. diospyrifolium a presença de camadas subepidérmicas em ambas as faces, destacando a necessidade de análises de desenvolvimento para revelar a natureza destas camadas.

A estrutura foliar de $P$. hispidum assemelha-se à de outras espécies de Piper já descritas, entretanto vale destacar que, em P. hispidinervium (Nascimento; VilhenaPotiguara, 1999), em P. aduncum (Vianna; Akisue, 1997) e em P. betle (Datta; Dasgupta, 1979), a hipoderme está restrita apenas a face adaxial.

Cristais aciculares de oxalato de cálcio foram observados, nas células do parênquima lacunoso, células parenquimáticas do pecíolo e da nervura mediana em $P$. hispidum. Metcalfe e Chalk (1950) destacam que três tipos de cristais podem ocorrer nas folhas de Piperaceae. Souza et al. (2004) observaram a presença de areia cristalífera em O. martiana, monocristais piramidais em Peperomia dahlstedtii e ráfides em $P$. diospyrifolium.

Canais ou células de conteúdo mucilaginoso, hidatódios e glândulas peroladas, também denominadas reluzentes, de conteúdo lipídico, foram mencionadas por Metcalfe e Chalk (1950), Salatino e Silva (1975) e Silva e Machado (1999) como estruturas comumente encontradas nos órgãos vegetativos de Piper. Entretanto, estas estruturas não foram observadas no presente estudo.

Os testes histoquímicos realizados mostraram a presença marcante de substâncias de origem lipídica e cristais de oxalato de cálcio, bem como amido, compostos fenólicos e alcalóides, estes últimos descritos por Dahlgren (1980) como alcalóides do grupo benzilisoquinolínicos.

De acordo com as descrições apresentadas e dicutidas para $P$. hispidum, pode-se concluir que, apesar da semelhança morfológica entre as espécies de Piperaceae, alguns caracteres anatômicos podem ser utilizados para a sua distinção, como por exemplo: faixas descontínuas de colênquima subepidérmico no caule; a localização e o número de estratos celulares da hipoderme na folha, os tricomas e sua localização, as células e os idioblastos oleíferos, bem como a natureza química de seu conteúdo.

\section{AGRADECIMENTOS}


Os autores agradecem a Dra. Elsie Franklin Guimarães, especialista do Jardim Botânico do Rio de Janeiro,

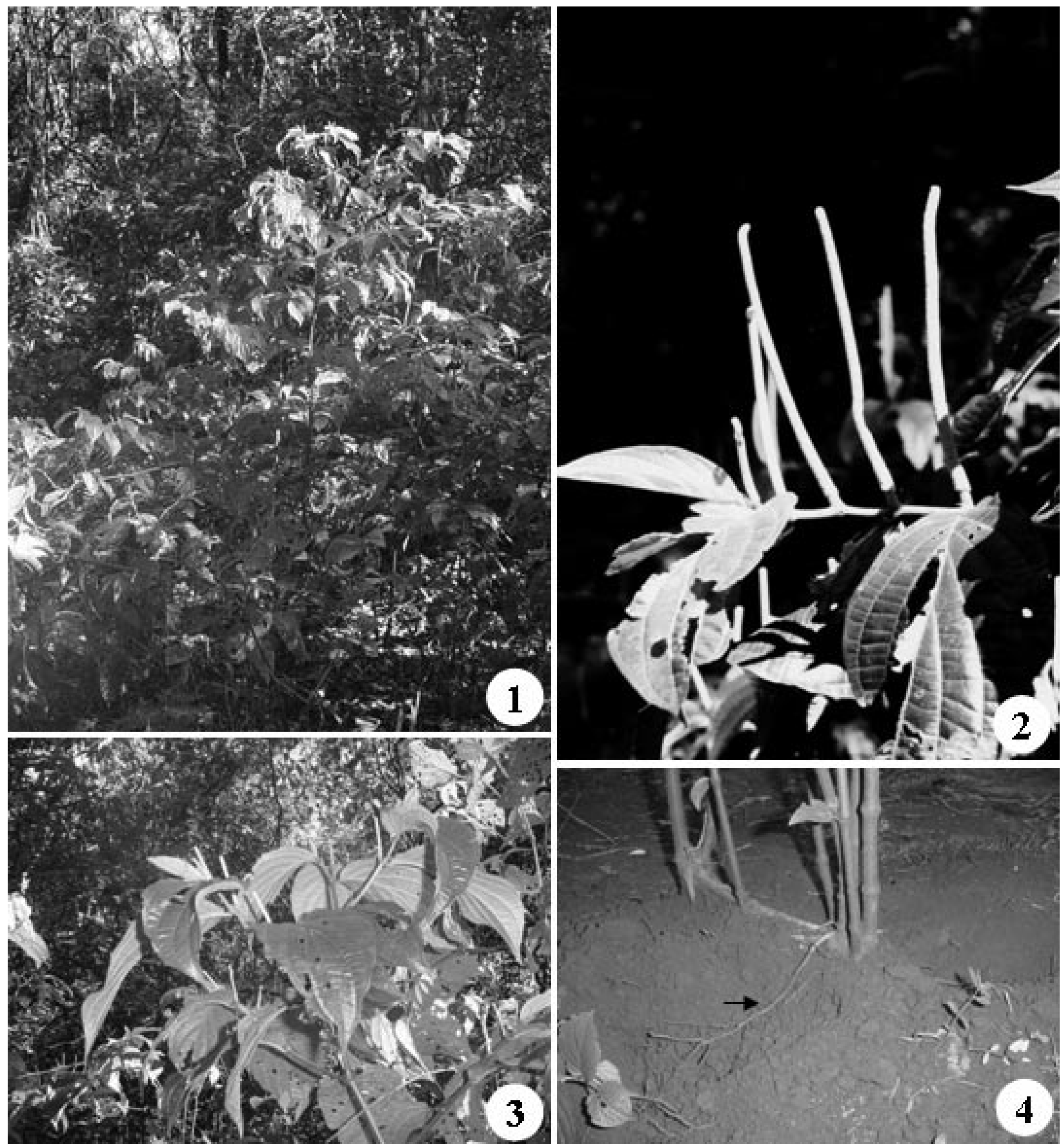

Figs. 1-4: Piper hispidum Sw. 1-2: Aspecto geral do espécime e evidenciando ramo com inflorescências; 3 - 4: Ramos e porção basal evidenciando raiz adventícia.

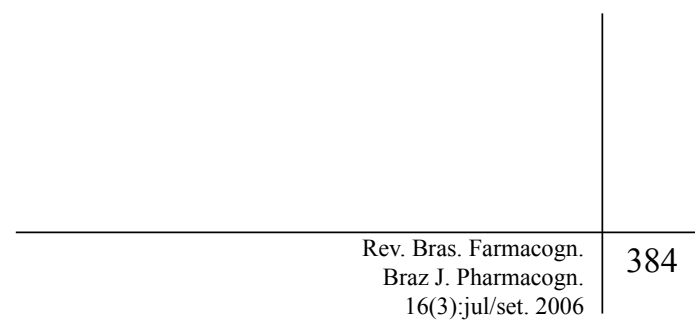




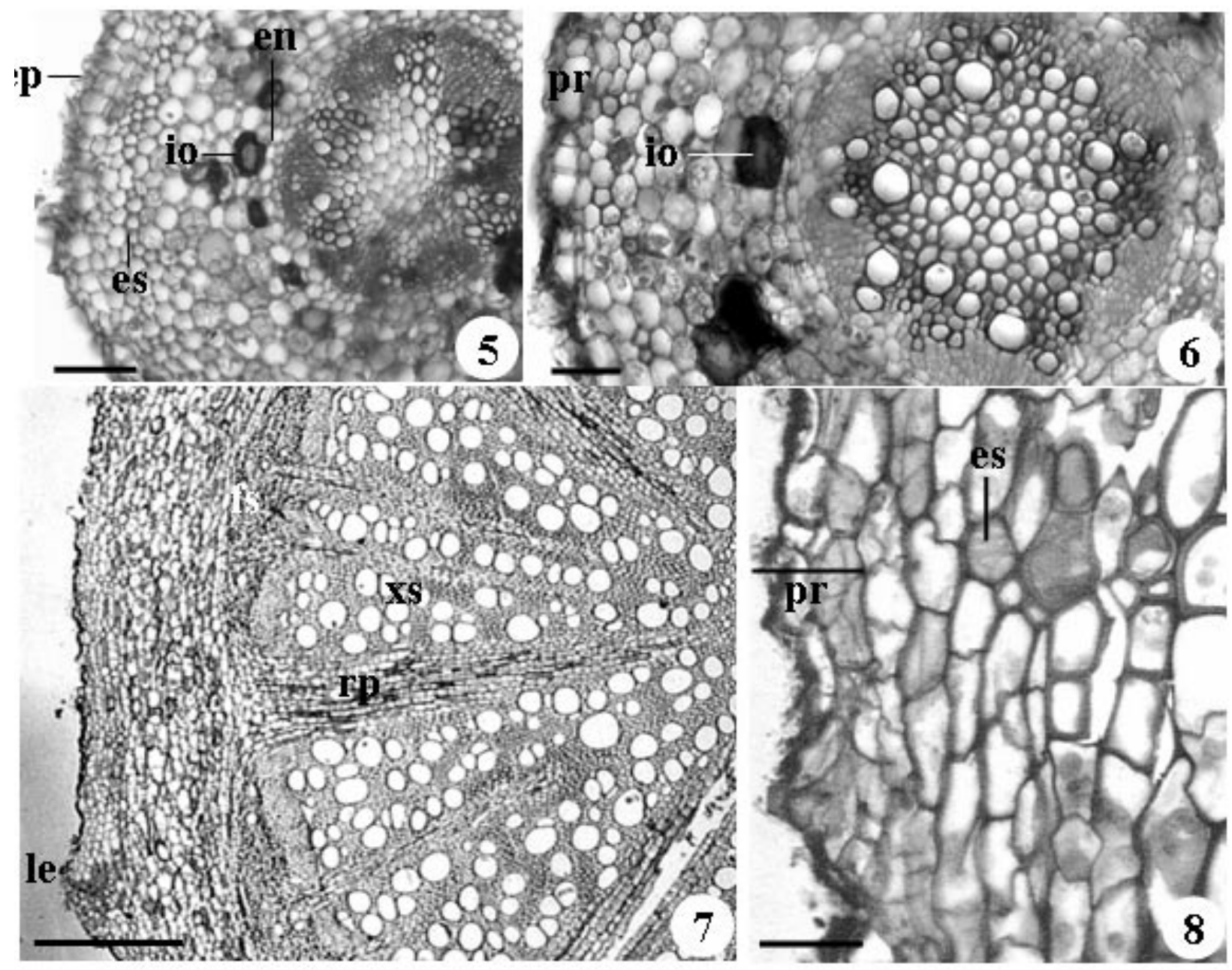

Figs. 5-8:Piper hispidum Sw. Seções transversais da raiz; 5:Em estrutura primária (barra- $100 \mu \mathrm{m}$ ) destacando células oleíferas e esclereídes; 6:Estrutura secundária inicial, destacando periderme (barra - $100 \mu \mathrm{m}) ; 7:$ Em crescimento secundário, destacando

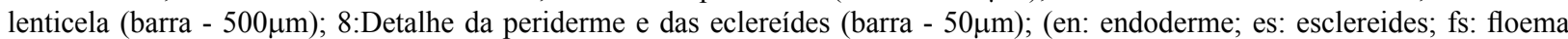
secundário; io: idioblasto oleífero; pr: periderme; rp: raio parenquimático; xs: xilema secundário). 

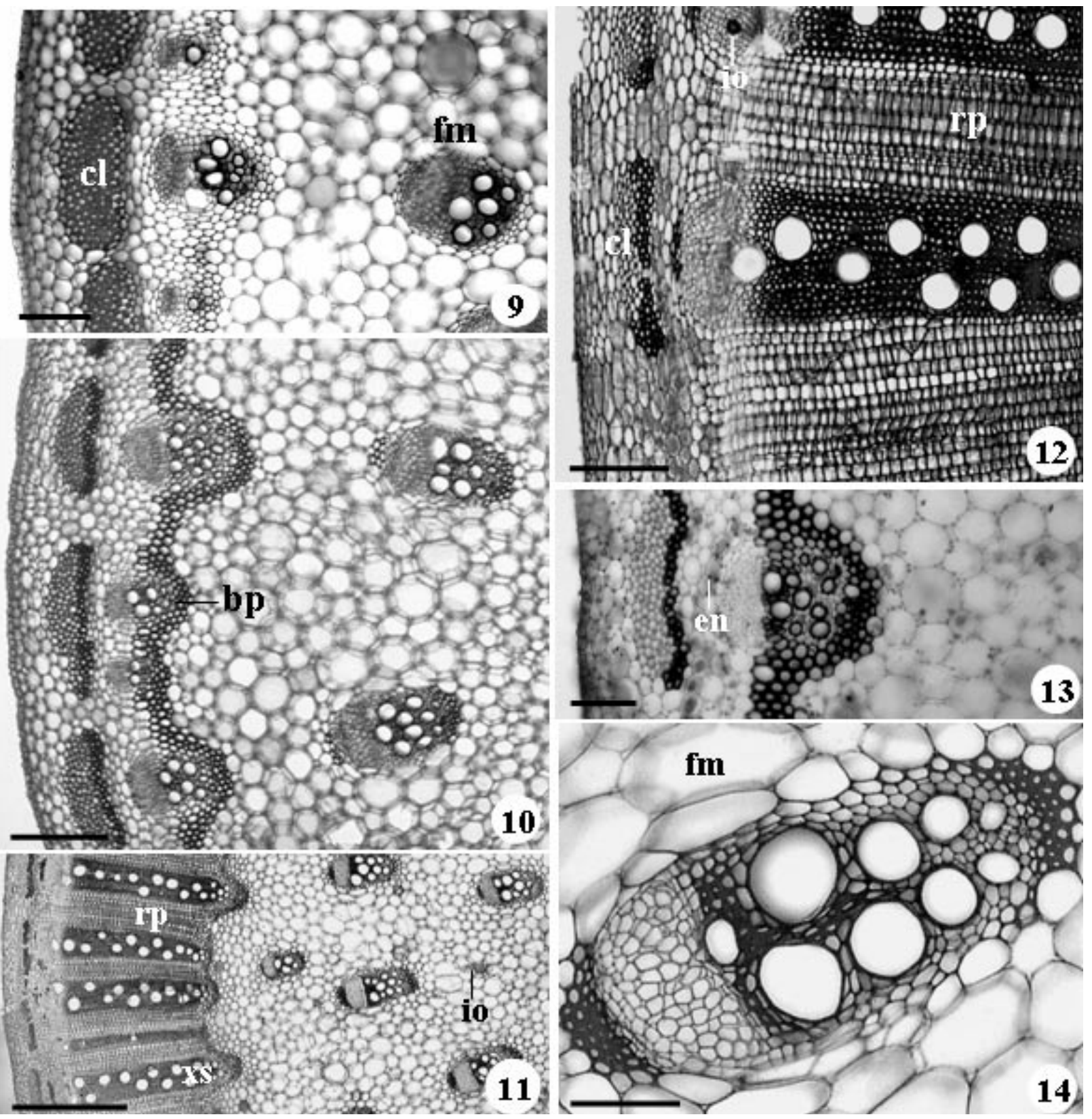

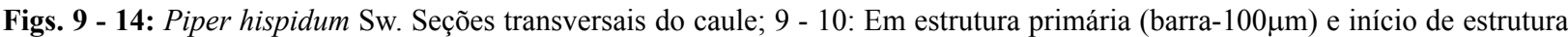

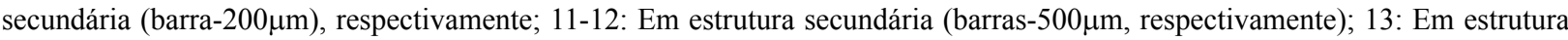

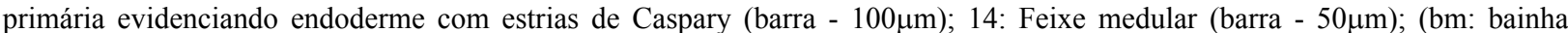
perimedular; cl: colênquima; fm: feixe medular; fs: floema secundário; en: endoderme; ep: epiderme; io: idioblasto oleífero; pr: periderme; rp: raio parenquimático; xs: xilema secundário).

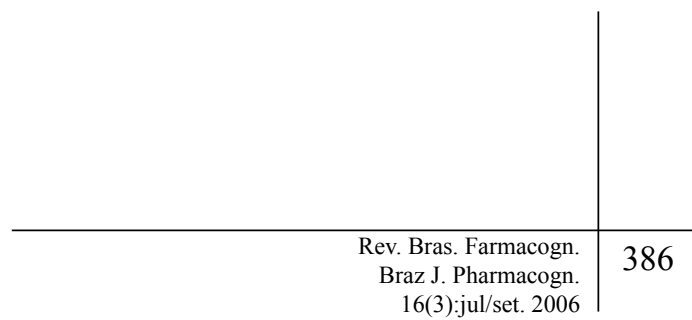



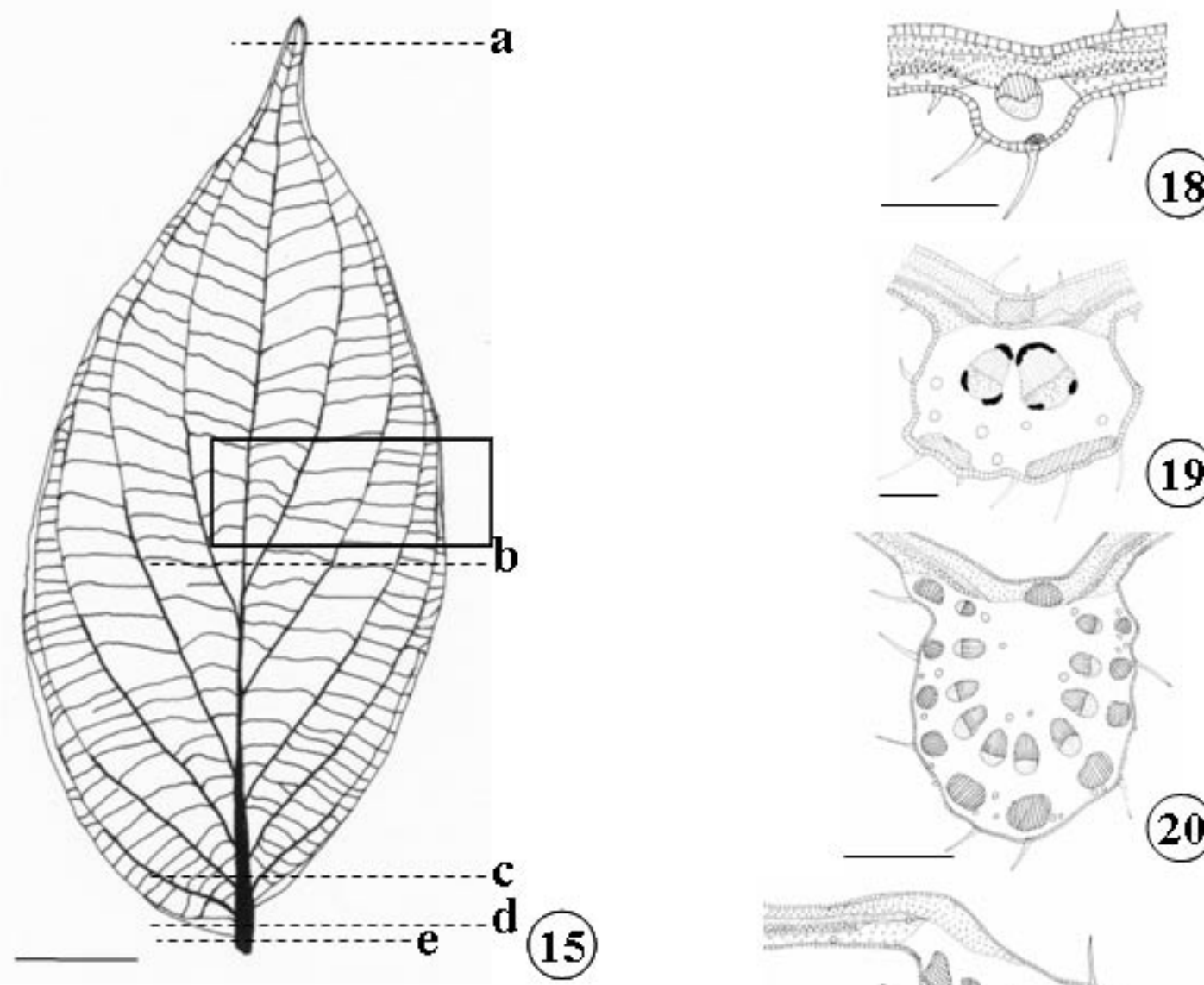

\section{(8)}
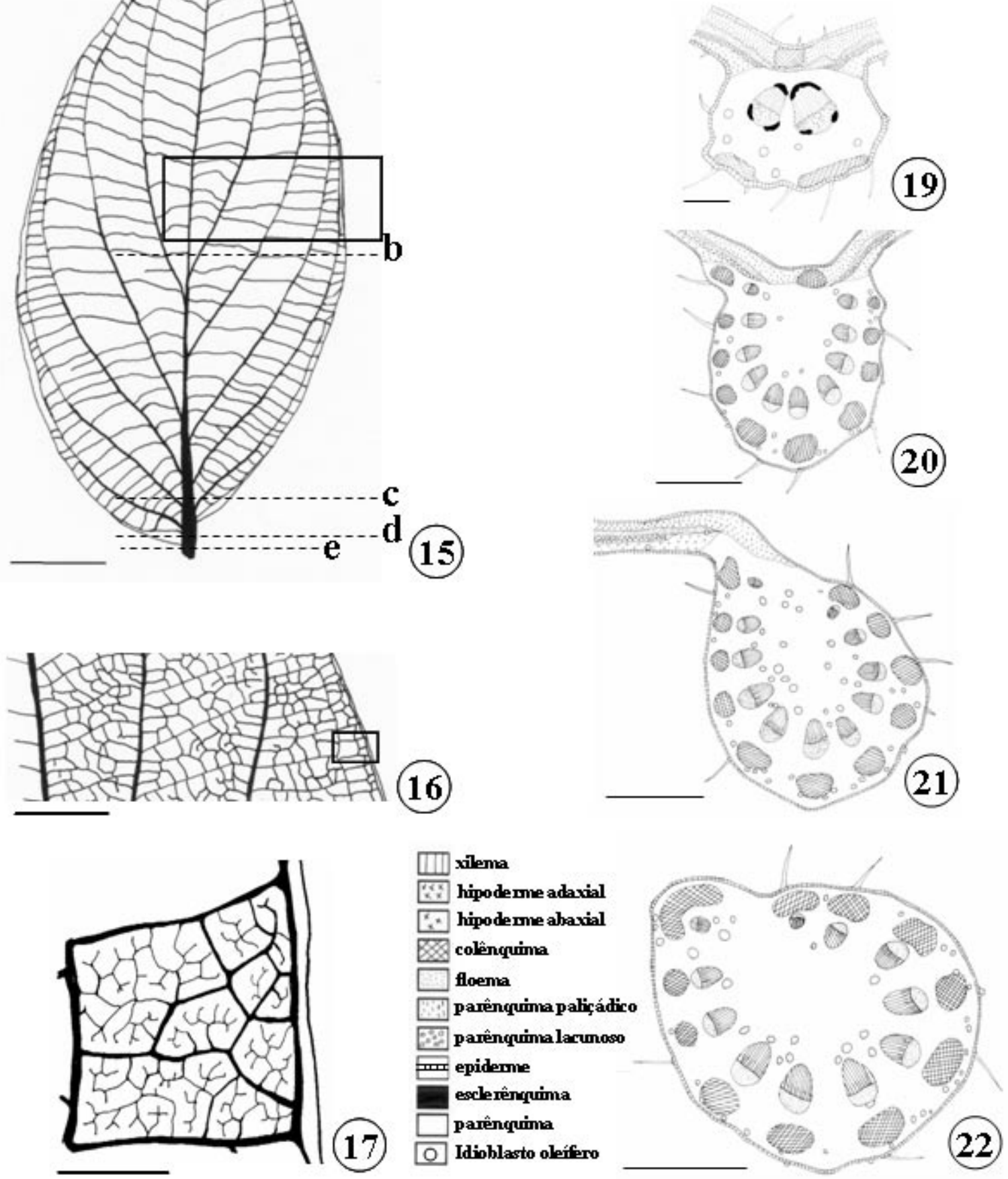

Figs. 15 - 22: Piper hispidum Sw. 15 -17: Venação; 15: Padrão geral (barra - 2cm); 16: Venação de ordens superiores (barra - 2cm) na região indicada pelo retângulo na Fig. 15; 17: aréolas e vênulas (barra - 1mm) na região indicada pelo retângulo na Fig.16; 18 - 22: Diagramas das seções transversais da nervura primária e do pecíolo nas regiões indicadas na Fig. 15 pelas letras de a-e; 18 :

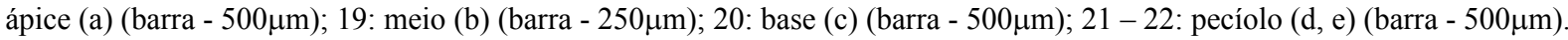



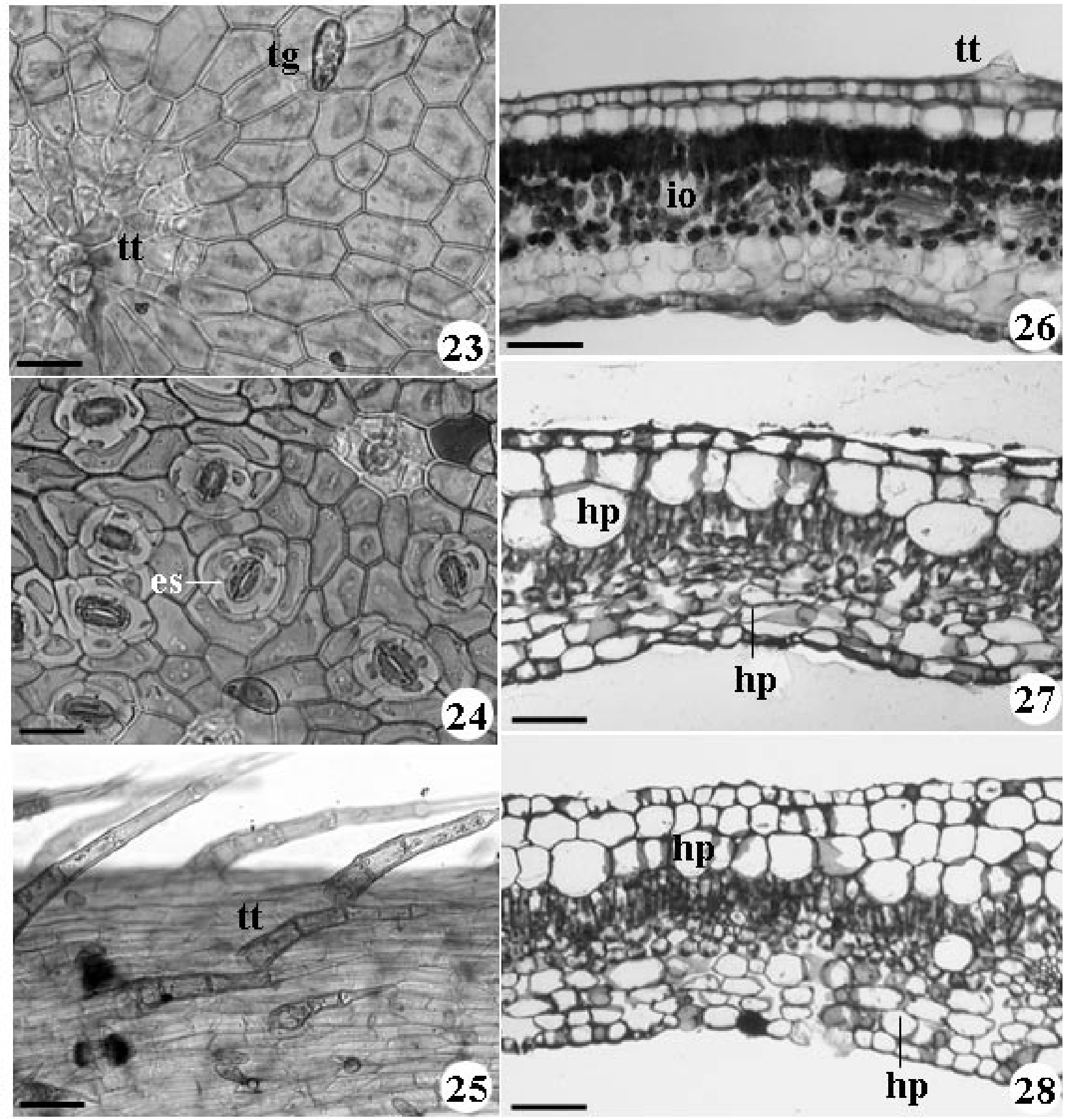

Figs. 23 - 28: Piper hispidum Sw. 23 - 24: Seções paradérmicas das superfícies adaxial e abaxial da epiderme, respectivamente

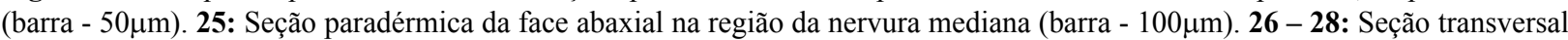

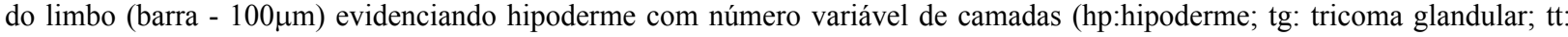
tricoma tector).

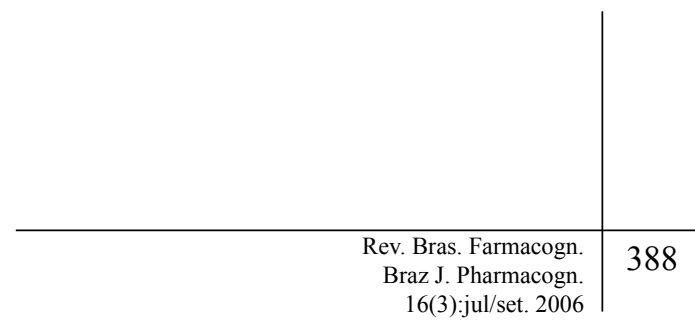



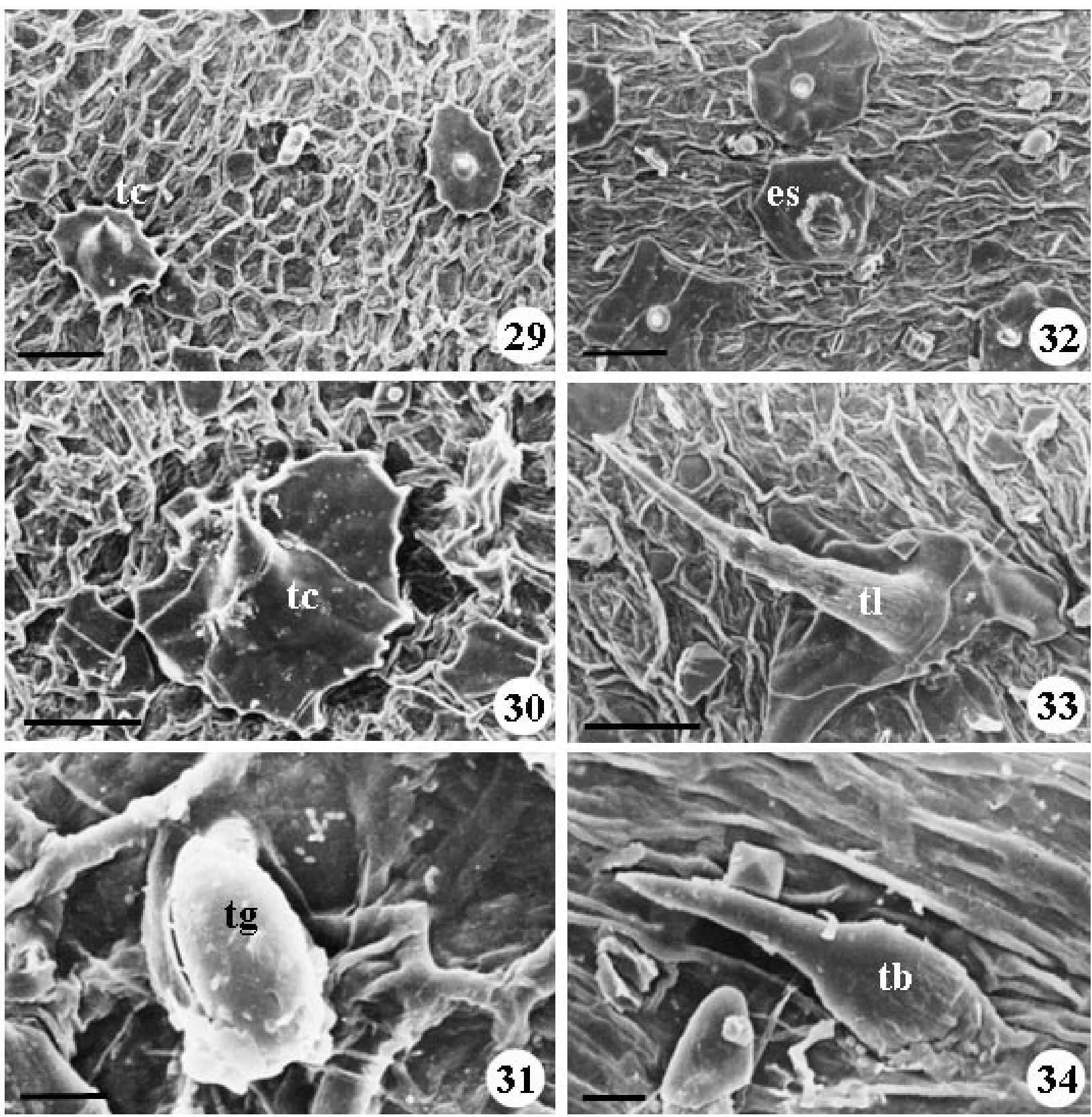

Figs. 29 - 34: Epiderme foliar de Piper hispidum Sw. vista em MEV. 29: Aspecto geral da face adaxial (barra - 50 $\mathrm{mm}$ ), 30: Tricoma

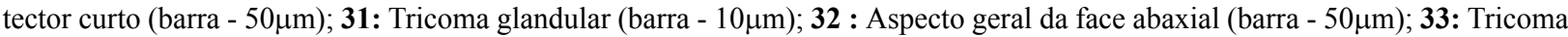

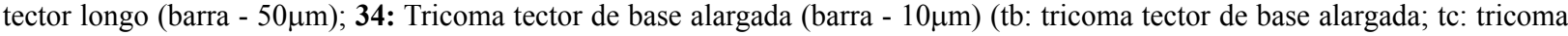
tector curto; tg: tricoma glandular; tl: tricoma tector longo). 


\section{REFERÊNCIAS}

Albiero ALM, Paoli AAS, Souza LA, Mourão KSM 2005. Morfoanatomia dos órgãos vegetativos de Piper crassinervium H.B.\&K. (Piperaceae). Acta Botanica Brasilica 19:305-312.

Barroso GM 1978. Sistemática das Angiospermas do Brasil. UFV, Viçosa.

Barthlott W, Neinhuis C, Cutler D, Ditsch F, Meusel I, Theisen I, Wilhelmi H 1998. Classification and terminology of plant epicuticular waxes. Bot J Linn Soc 126: 237-260.

Burger WC 1958. The Piperales and the monocots. Bot Rev 43:345-398.

Cronquist A 1981. An Integrated System of Classification of Flowering Plants, Columbia University Press, New York.

Dahlgren RMT 1980. A revised system of classification of angiosperm. Bot J Linn Soc 80: 91-124.

Dahlgren RMT, Clifford HT 1982. The Monocotyledons: A comparative study. Academic Press, London.

Dasgupta A, Datta PC 1980. Medicinal species of Piper, pharmacognostic delimitation. QJ Crude Drug Res 18: $17-25$.

Datta PC, Dasgupta A 1979. Comparison of vegetative anatomy of Piperales III. Vascular supplies to leaves. Acta Botanica Indica 7: 39-46.

Fahn A 1979. Secretory Tissues in Plants. Academic Press, London.

Figueiredo RA, Sazima M 2000. Pollination biology of Piperaceae species in southeastern Brazil. Ann Bot 85: 455-460.

Fuchs $\mathrm{CH}$ 1963. Fuchsin staining with $\mathrm{NaOH}$ clearing for lignified elements elements of whole plants or plants organs. Stain Technology 38: 141-144.

Furr M, Mahlberg PG 1981. Histochemical analyses of lacticifers and glandular trichomes in Cannabis sativa. J Nat Prod 44: 153-159.

Gabe M 1968. Techniques Histologiques, Masson \& Cie., Paris.

Gerlach G 1969. Botanishe Microtechnik. Eine Einfürhrung George Thiem, Stuttgard.

Gerrits PO 1991. The Application of Glycol Methacrylate in Histotechnology; some fundamental principles. University Groningen, Netherlands.

Hickey LJ 1973. Classification of the architecture of Dicotyledonous leaves. Am J Bot 60: 17-33.

Hutchinson J The Families of the Flowering Plants. 1973. $3^{\text {th. }}$ ed. Claredon Press, London

Jensen WA 1962. Botanical Histochemistry: principle and practice. Freeman, San Francisco.

Johansen DA 1940. Plant Mycrotechnique. Mc Graw Hill Books, New York

Judd WS, Campbell CS, Kelogg EA, Steven PF 1999. Plant Systematics, a Phylogenetic Approach. Sinauer Associates, Inc. Publishers, Sunderland.

Langhammer VL 1970. Piper auritum H.B.K. - An anatomicalhistochemical study. Piperaceae used in folk medicine. A comparative anatomical-histochemical study. Planta Med 19: 63-70.

Lersten NR1997. Occurrence of the endodermis with a Casparian strip in stem and leaf. Bot Rev 63: 265272.
Mace ME, Howell CR 1974. Histochemistry and identification of condensed tannin precursor in roots of cotton seedlings. Can J Bot 52: 2423-2426.

Mauseth JD 1988. Plant Anatomy. The Benjamim-Cummings Publishing Company, California.

Melo-de-Pinna GFA, Menezes NL 2002. Vegetative organ anatomy of Ianthopappus corymbosus (AsteraceaeMutisieae). Rev Bras Bot 25: 505-514.

Mesquita JMO, Cavaleiro C, Cunha AP, Lombardi JA, Oliveira AB 2005. Estudo comparativo dos óleos voláteis de algumas espécies de Piperaceae. Rev Bras Farmacogn 15: 6-12.

Metcalfe CR, Chalk L 1950. Anatomy of the Dicotyledons. Pp. 1120-1133, Claredon Press, Oxford.

Mohandas KK, Shah GL 1982. Structure and ontogeny of trichomes in some Piperaceae. Acta Botanica Indica 10: 92-95.

Moraes MS 1986. Considerações sobre a pariparoba oficial Pothomorphe umbellata (L.) Miq. Rev Bras Farmacogn 1: 101-108.

Murty YS 1960. Studies in order Piperales I. A contribution to the study of vegetative anatomy of the some species of Peperomia. Phytomorphology 10: 50-59.

Nascimento ME, Vilhena-Potiguara CR 1999. Aspectos anatômicos dos órgãos vegetativos de Piper hispidinervium C. DC. (Piperaceae) e suas estruturas secretoras. Boletim do Museu Paraense Emílio Goeldi; Série Botânica 15: 39-104.

Navickiene HMD, Alécio AC, Kato MJ, Bolzani VS, Young MCM, Cavalheiro AJ, Furlan M 2000. Antifungal amides from Piper hispidum and Piper tuberculatum. Phytochemistry 55: 621-626.

O’Brien TP, Feder N, McCully ME 1965. Polycromatic staining of plant cell walls by toluidine blue O. Protoplasma 59: 368-373.

Pessini GL, Albiero ALM, Mourão KSM, Nakamura CV, DiasFilho BP, Cortez DA 2003. Acta Farma Bonaerense 22: 209-216.

Potzernheim MCL, Bizzo HR, Vieira RF 2006. Análise dos óleos essenciais de três espécies de Piper coletadas na região do Distrito Federal (Cerrado) e comparação com óleos de plantas procedentes da região de Paraty, RJ (Mata Atlântica). Rev Bras Farmacogn 16: 246-251.

Radford AE, Dickson WC, Massey JR, Bell CR 1974. Vascular Plant Systematics. Harper \& Row Publischers, New York.

Robards AW 1978. An introduction to techniques for scanning electron microscopy of plant cells. In: Electron Microscopy and Cytochemistry of Plant Cells. Elsevier, New York.

Salatino A, Silva JB 1975. Anatomia e óleo essencial das folhas de Piper regnellii (Miq.) C.CD. var. regnellii. Boletim de Botânica da Universidade de São Paulo 3: 95-106.

Sass JE 1951. Botanical Microtechnique. $3^{\text {rd }}$ ed., State College Press, Iowa.

Silva EM, Machado SR 1999. Estrutura e desenvolvimento dos tricomas secretores em folhas de Piper regnellii (Miq.) C.DC. var. regnellii (Piperaceae). Rev Bras Bot 22: 117-124.

Souza LA, Moscheta IS, Oliveira JHG 2004. Comparative morphology and anatomy of the leaf and stem of 
Peperomia dahlstedtii, Ottonia martiana and Piper diospyrifolium (Piperaceae). Gayana Botanica 61: 6-17.

Svendsen AB, Verpoorte R 1983. Chromatography of Alkaloids. Elsevier Scientific Publishing Company, New York.

Takemori NK 2002. Anatomia Comparada de Peperomia catharinae, Peperomia emarginella, Peperomia quadrifolia e Peperomia rotundifolia (Piperaceae). Dissertação de Mestrado, Universidade Federal do Paraná, Curitiba, 69p.

Takemori NK 2003. Anatomia comparada das folhas de espécies de Peperomia (Piperaceae). I. Onteogênese do tecido aqǘ́fero e dos estômatos. Acta Botanica Brasilica 17: 387-394.

Vianna WO, Akisue G 1997. Caracterização morfológica de Piper aduncum L. Lecta 15: 11-62.

Yuncker TG 1958.The Piperaceae - A family profile. Brittonia 10: 1-7.

Yuncker TG 1972.The Piperaceae of Brazil I - Piper - group I, II, III, IV. Hoehnea 2: 19-366.

Yuncker TG 1973. The Piperaceae of Brazil II - Piper - group V Ottonia, Pothomorphe, Sarcorhachis. Hoehnea 3: 29-284. 